\title{
ERRATUM
}

\section{Erratum to "Effect of Tunnel Filters on Flow Characteristics in an Eight-strand Tundish" [ISIJ International, 57 (2017), No. 11, pp. 1990-1999]}

Xiao-ying WANG, ${ }^{1,2)}$ Dan-ting ZHAO, ${ }^{3)}$ Sheng-tao QIU ${ }^{2)}$ and Zong-shu ZOU ${ }^{1)}$

1) School of Metallurgy, Northeastern University, Shenyang, 110819 China.

2) Center for Continuous Casting Technology Research, Central Iron \& Steel Research Institute, Beijing, 100081 China.

3) School of Metallurgical and Chemical Engineering, Jiangxi University of Science and Technology, 341000 China.

DOI: http://dx.doi.org/10.2355/isijinternational.ISIJINT-2017-165

Correction of the picture was reported in the above paper by Authors.

The authors have found that the Fig. 15 reported in the above paper is inappropriate, the magnification of the quondam image used for comparative analysis is inconsistent, and it lead to the comparison is rather laborious. The authors would like to correct the Fig. 15 as follows:

Original image:

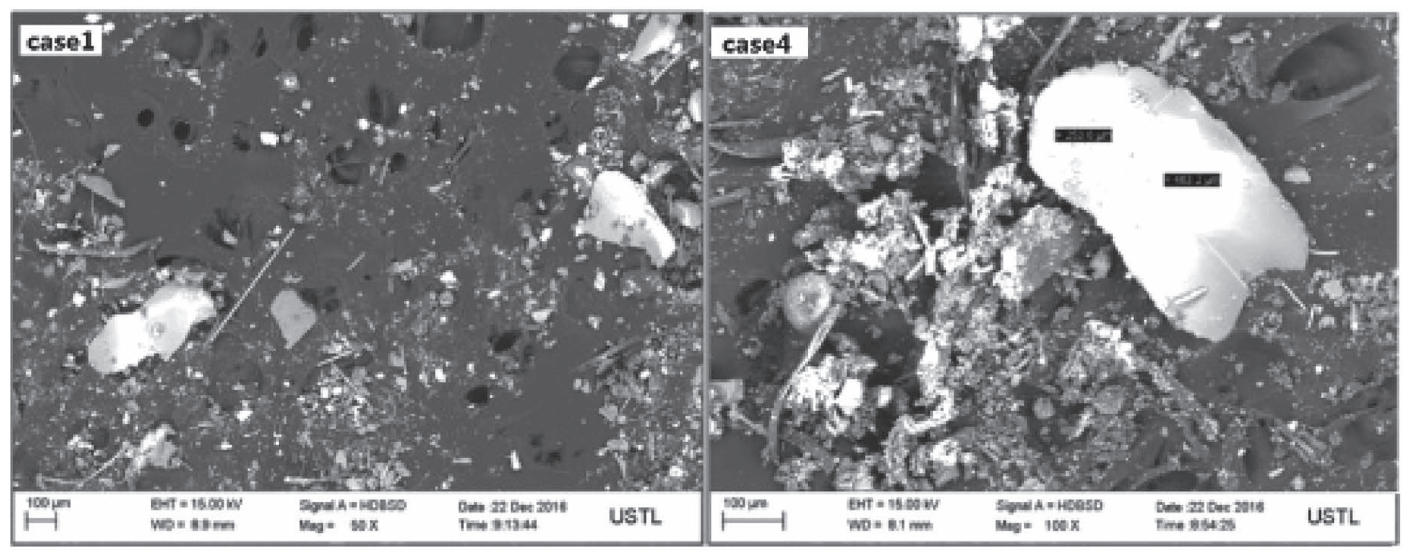

(a) The impact region samples

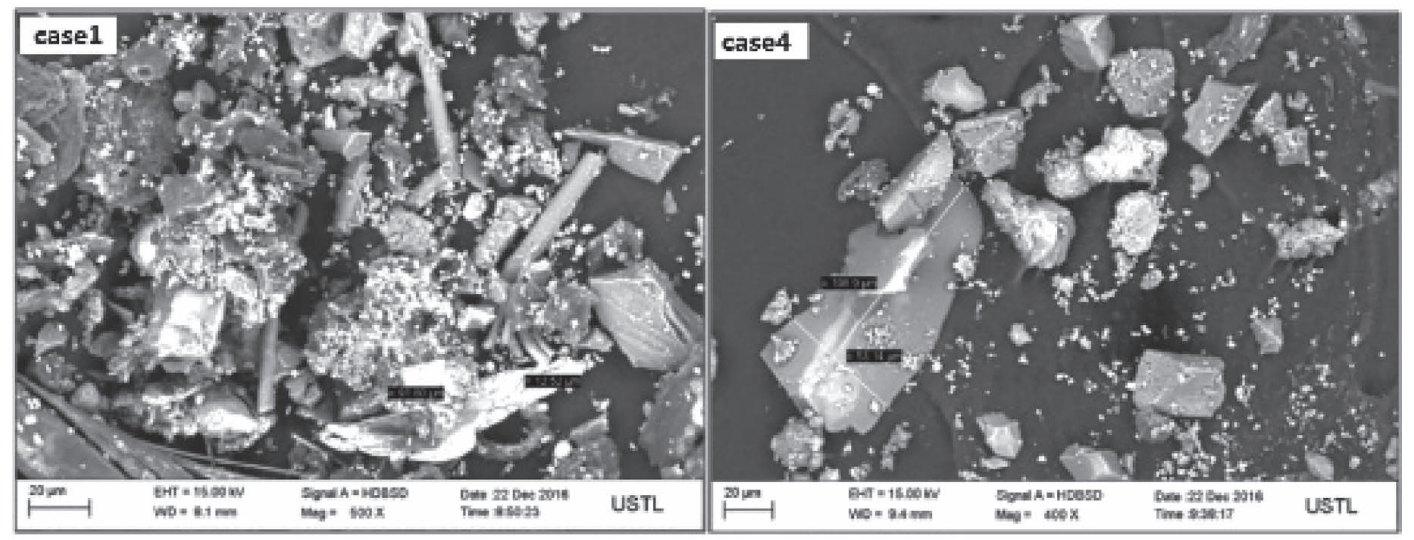

(b) The pouring region samples

Fig. 15. The SEM of tundish specimens electrolytic extraction. 
Modified image:

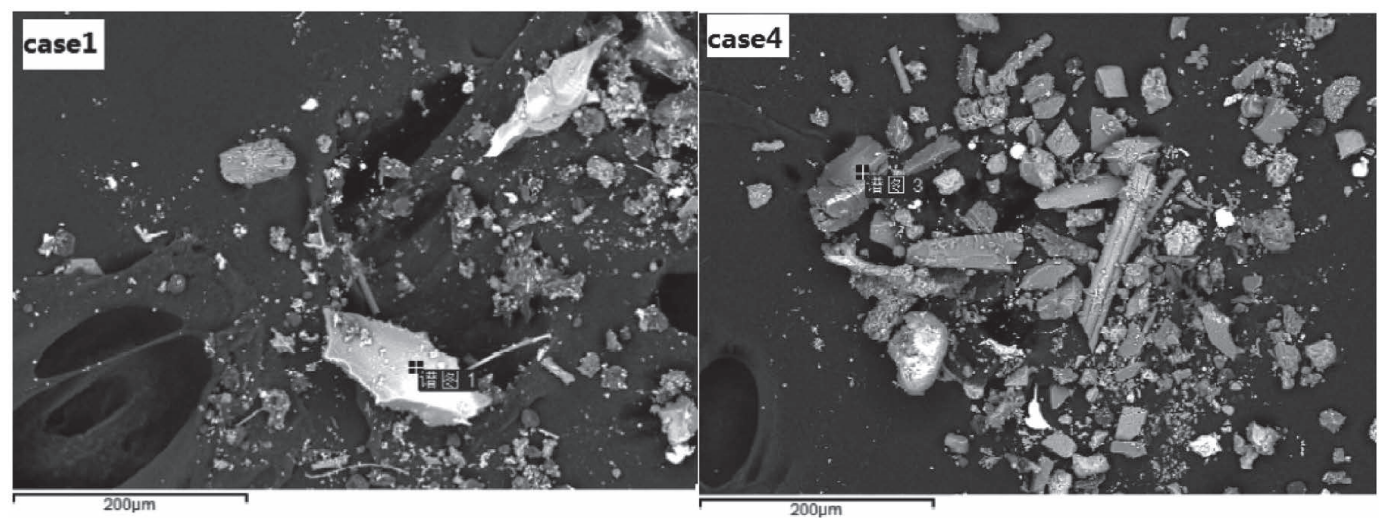

(a) The impact region samples

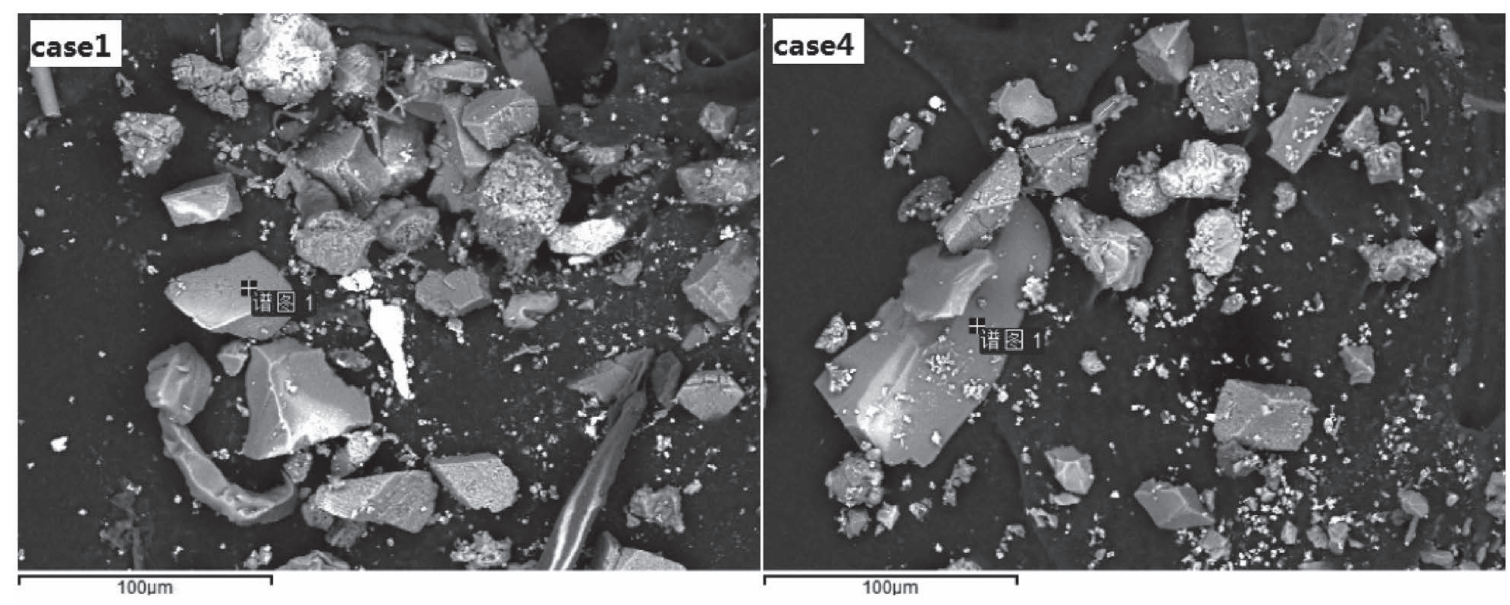

(b) The pouring region samples

Fig. 15. The SEM of tundish specimens electrolytic extraction. 